\title{
Synchronized intermittent mandatory ventilation mode based on deep sedation combined with nerve block improve postoperative pulmonary function in elderly patients undergoing hip arthroplasty:a randomized controlled trial
}

\section{Yang Zhang}

Department of Anesthesiology, the Second Affiliated Hospital of Anhui Medical University

Yun Li

Department of Anesthesiology, the Second Affiliated Hospital of Anhui Medical University

Di Fan

The Second Affiliated Hospital of Anhui Medical University

Rui Li

The Second Affiliated Hospital of Anhui Medical University

Xianwen $\mathrm{Hu}$

The Second Affiliated Hospital of Anhui Medical University

Ye Zhang ( $\nabla$ zhangye_hassan@sina.com )

Department of Anesthesiology, the Second Affiliated Hospital of Anhui Medical University

\section{Research article}

Keywords: volume-controlled ventilation, synchronized intermittent mandatory ventilation, pulmonary function, postoperative pulmonary complications

Posted Date: December 16th, 2019

DOl: https://doi.org/10.21203/rs.2.18812/v1

License: (c) (i) This work is licensed under a Creative Commons Attribution 4.0 International License.

Read Full License 


\section{Abstract}

Background: Hip arthroplasty is currently the gold standard for the treatment of femoral neck fractures in elderly patients. General anesthesia is common in hip arthroplasty and usually requires mechanical ventilation. Elderly patients are prone to various complications, notably pulmonary complications that occur due to poor cardiac-pulmonary function following surgery.

Methods: The anesthesia method used in the patients undergoing hip arthroplasty in the present study was mainly based on nerve blocks combined with deep sedation. Patients were randomly divided into two groups according to the different ventilation modes. Subsequently, the differences between the two groups were evaluated by observing the intraoperative airway pressure, the perioperative blood gas analysis, the pulmonary function and the postoperative pulmonary infection score.

Results: A total of 63 patients were finally enrolled and analyzed, of which 31 were with Volumecontrolled ventilation (VCV) and 32 with Synchronized intermittent mandatory ventilation (SIMV). The airway pressure at the $0.5 \mathrm{~h}$ and $1 \mathrm{~h}$ after the insertion of laryngeal mask airway (LMA) and clinical pulmonary infection scores at the time of postoperative day3 and day 5 in the SIMV group were significantly lower than that of the VCV group $\mathbb{P}<0.05 \bigotimes$. In spite of the results indicated that both groups of patients underwent a decline in pulmonary function an blood gas postoperatively, the mean values of the parameters of pulmonary function and blood gas analysis in the SIMV group from the time periods T1 to T3 were better than those of the VCV group $(P<0.05)$.

Conclusions: The SIMV mode can improve postoperative pulmonary function and reduce postoperative pulmonary complications (PPCs), such as pulmonary infection compared with the VCV group. This leads to lung-protective ventilation. This mode should be used to optimize anesthesia-related strategies and to accelerate the rapid postoperative recovery of the patients.

\section{Background}

Hip arthroplasty is the surgical replacement of the hip joint that has been damaged by disease or injury with an artificial joint. It has been used extensively in clinical practice and is preferred for relieving joint pain and improving joint function compared to other surgical interventions [1, 2]. However, this operation is notably traumatic, and the patients undergoing the surgery are mostly elderly that often have other underlying diseases and reduced compensatory functions [3]. For these reasons, patients are prone to various complications following surgery $[4,5]$.

Previous studies have shown that the probability of postoperative pulmonary complications (PPCs) in patients aged 60-69 and 70-79 years old is 2- and 3-fold that of patients under 60 years of age, respectively [6]. $5 \%$ of patients experience PPCs and they have a much higher 30-day mortality rate than patients without PPC (19.5\% vs. 0.5\%) [7]. PPC seriously affects surgical outcome and can affect elderly patient survival $[8,9]$. 
General anesthesia is common in hip arthroplasty and usually requires mechanical ventilation. Previous research has shown that $90 \%$ of general anesthesia is associated with atelectasis and in $10-20 \%$ of the cases, the lung tissue adjacent to the diaphragm can collapse $[10,11]$. The tissue can remain collapsed for several days following surgery and mechanical ventilation during general anesthesia may be an important contributing factor to pulmonary complications $[12,13]$.

Volume-controlled ventilation (VCV) is currently the most commonly used mode of mechanical ventilation [14]. This ventilation mode is designed to increase the air flow and airway pressure during the inspiratory phase and aims to open small airways to achieve successful ventilation. Synchronized intermittent mandatory ventilation (SIMV) mode provides mandatory ventilation through a ventilator according to preset breathing parameters. When spontaneous breathing occurs within the trigger window, the ventilator assists with spontaneous breathing and compensates for inadequate spontaneous breath volume. In the absence of spontaneous breathing inside the trigger window, intermittent positive pressure ventilation is provided at the end of the trigger window [15].

In the present study, the effects of these two different ventilation modes, VCV and SIMV, on postoperative pulmonary function and PPCs were investigated in elderly patients undergoing hip arthroplasty. The results can provide guidance for the selection of suitable lung ventilation regimes, individualized PPC prevention strategies, and preoperative respiratory management.

\section{Methods}

The randomized clinical two-arm parallel study has been approved by the Medical Ethics Committee of the second hospital of Anhui medical university, Hefei, China (Approval No: PJ2016-019-01). All patients signed written informed consent forms prior to their participation in the study protocol. The trial was registered before patient enrollment at the Chinese Clinical Trial Registry (ChiCTR1900024303; principal investigatorखYe Zhang; date of registration, July 5th, 2019).

\section{Participants and randomization}

A total of 80 patients aged 65-85 years underwent hip arthroplasty admitted to the Second Affiliated Hospital of Anhui Medical University between July 2019 and September 2019 were included in this study (Figure 1). The inclusion criteria were the following囚all were classified as class II or III according to the American Society of Anesthesiologists (ASA) physical status and had no history of mental illness, neurological disease, severe heart, lung, liver, or kidney disease, or evident thoracic or spinal deformity. Exclusion criteria were冈serious respiratory or circulatory diseases, such as severe atherosclerosis of coronary artery, arrhythmia, cardiac valve pathologies, arteriosclerosis, cardiac pacemaker, automated implantable cardioverter defibrillator, cardiac failure, chronic obstructive pulmonary disease and obvious liver or kidney dysfunction. 
A computer-based list was generated (www.random.org), and subjects were randomly assigned (sequence number use, opaque, sealed envelopes) to a set of two groups: VCV group (V-group) and SIMV group (S-group). Written informed consent was obtained before the recruitment of subjects in the study. Researchers not involved in the treatment of perioperative assessment of outcome variables, and group assignments and intervention knowledge.

\section{Intervention}

The patient examination included peripheral venous access, blood pressure (BP) measurement, electrocardiogram (ECG), oxygen saturation $\left(\mathrm{SpO}_{2}\right)$, and sedation depth-bispectral index (BIS). In addition, radial artery catheterization was performed under local anesthesia to monitor the invasive arterial pressure of the patients. Prior to the induction of anesthesia, each patient was administered $20 \mathrm{ml}$ of $0.375 \%$ ropivacaine under the guidance of ultrasound or neurostimulator in order to block the lumbar plexus block, sacral plexus, or both. The blocking effect was confirmed. Anesthesia was achieved using $8 \%$ sevoflurane for tidal volume induction. Once the patients lost consciousness, $0.15 \mathrm{mg} / \mathrm{kg}$ cisatracurium was administered via intravenous bolus injection. When the sedation depth value fell below 60 , the laryngeal mask airway (LMA) was placed, followed by connection to a Mindray anesthesia machine for controlled ventilation. The parameter settings were as follows: The ventilation was set to tidal volume $8 \mathrm{ml} / \mathrm{kg}$, the respiratory frequency ranged from 10 to 15 times $/ \mathrm{min}$, the inspiratory/expiratory phase ratio was $1: 2$, the pressure limit was $30 \mathrm{~cm} \mathrm{H}_{2} \mathrm{O}$, the inhaled oxygen concentration reached $60 \%$, and the flow rate was $2 \mathrm{l} / \mathrm{min}$. The end-tidal $\mathrm{CO}_{2}$ pressure $\triangle P E T \mathrm{CO}_{2} \rrbracket$ ranged from 30 to $40 \mathrm{mmHg}$. To maintain anesthesia, sevoflurane inhalation and intravenous dexmedetomidine were provided according to the BIS value (maintained between 60 and 70). These anesthetics were used to monitor the depth of general anesthesia, and their doses were adjusted accordingly. The hemodynamic stability of each patient was maintained. In the case that the mean arterial pressure was reduced to more than $30 \%$ compared with that of the basal value, $40 \mu \mathrm{g}$ phenylephrine was administered intravenously. In the case that the mean arterial pressure was increased to more than $30 \%, 10 \mathrm{mg}$ urapidil was administered intravenously.

Dexmedetomidine was discontinued 30 min prior to the end of surgery, and sevoflurane was discontinued and flushed out $10 \mathrm{~min}$ prior to the end of surgery. The muscle relaxation was antagonized with neostigmine and atropine. The tracheal tube was removed from each patient once he or she had recovered from anesthesia and achieved the extubation indications. The extubation indications were as follows: the patient was awake, could follow instructions, and met the criteria of 14-20 spontaneous breaths per min, $10 \mathrm{~min}$ air intake, $\mathrm{SpO}_{2}>92 \%$, and $\mathrm{PETCO}_{2}<45 \mathrm{mmHg}$. A patient-controlled intravenous analgesia (PCIA) pump was applied postoperatively for analgesia $(3 \mu \mathrm{g} / \mathrm{kg}$ sufentanil $+3 \mathrm{mg}$ granistron pre-diluted in $100 \mathrm{ml}$ normal saline) at a loading dose of $2 \mathrm{ml}$, a background dose of $2 \mathrm{ml} / \mathrm{h}$, a single dose of $2 \mathrm{ml}$, a $15 \mathrm{~min}$ locking time, and $48 \mathrm{~h}$ analgesia to keep the postoperative visual analog scale (VAS) score for pain $\leq 3$.

\section{Outcome measurement}


The primary endpoint was pulmonary function. A PONY FX spirometer (COSMED, Italy) was used for pulmonary function monitoring of forced vital capacity (FVC), forced expiratory volume (FEV) during the first second, and maximal voluntary ventilation (MVV) at the following times: upon entering the operating room (T0), at postoperative day 1 (T1), at postoperative day 3 (T2), and at postoperative day 5 (T3). At each time point, three measurements were obtained and the largest value was recorded.

The second endpoints included airway pressure, arterial blood analysis, pulmonary infection and duration of hospitalization. The peak airway pressure was measured at $5 \mathrm{~min}, 0.5 \mathrm{~h}$, and $1 \mathrm{~h}$ following the insertion of LMA. A GEM Premier 3500 blood gas analyzer (Werfen Instrumentation Laboratory, San Diego, CA, US) was used for blood gas analysis of arterial blood samples collected at the following time points (oxygen inhalation temporarily stopped $30 \mathrm{~min}$ prior to blood collection) as follows: prior to anesthesia induction (T0), prior to extubation (T1), at the time of exit from the anesthesia intensive care unit (AICU) (T2), and at postoperative day 1 (T3). The patient clinical pulmonary infection scores (CPIS) were reviewed on postoperative day 1 (T1), postoperative day 3 (T2), and postoperative day 5 (T3) to evaluate pulmonary infections. The duration of hospitalization of each patient was also recorded. All results were recorded by researchers that were not familiar with the group allocation.

\section{Statistical analyses}

The sample size calculation based on the preliminary trial results of postoperative pulmonary function. We aimed to detect the postoperative value of FVC in the SIMV group was $5 \%$ higher than that of the VCV group with a power of $80 \%$ and a two-sided significance level of $5 \%$, the calculated sample size was 29 subjects per group.

In the present study, the SPSS 17.0 software (IBM SPSS Inc., Chicago, IL, US) was used for statistical analysis. Normally distributed measurement data were presented as mean \pm standard deviation (i \pm s). Measurement data from a randomized block design were compared using the student's t-test. Measurement data of repeated measurement design were compared using the repeated measures ANOVA. Categorical variables were compared using the chi-squared test. A $P$ value lower than 0.05 $(P<0.05)$ was considered statistically significant.

\section{Results}

The CONSORT diagram is shown in the Figure 1. Among 80 patients in the present study, 17 patients were excluded (six did not met the inclusion criteria, nine chose not to participate in the study, and two did not complete the study). Finally, 63 clinical cases were divided into the VCV $(n=31)$ and SIMV $(n=32)$ groups based on their ventilation modes (Figure 1). No differences were noted between the two groups with regard to patient characteristics (Table 1). The experimental results evaluating the effect of the two ventilation modes on intra-operative airway pressure demonstrated that the airway pressure at the 0.5 and $1 \mathrm{~h}$ time points was higher than at 5 min following the insertion of LMA in the VCV group. However, no differences in the airway pressure were noted between these three time points in the SIMV group. In 
addition, the airway pressure in the SIMV group at the $0.5 \mathrm{~h}$ and $1 \mathrm{~h}$ time points after the insertion of laryngeal mask airway $(L M A)$ was significantly lower than that of the VCV group $(P<0.001)$ (Table 3$)$.

The effects of the two different ventilation modes on the pressure of the arterial blood gases were evaluated at different times. Since $60 \%$ oxygen was inhaled during anesthesia, oxygen inhalation was discontinued 30 min prior to the patient exit from the Anesthesia Intensive Care Unit (AICU). Arterial blood gas was further measured at the same time point (T2). The results demonstrated that the arterial blood gas of all patients at T3 was lower than values noted at T0, to different extents. Lactic acid (Lac) was lower in the SIMV group than that noted in the VCV group at T1 and T2 $(\mathrm{P}<0.05)$. In addition, Partial pressure of carbon dioxide $\otimes \mathrm{PaCO}_{2} \otimes$ was lower in the SIMV group compared with that noted in the VCV group at $\mathrm{T} 2$ and $\mathrm{T} 3(\mathrm{P}<0.05)($ Table 4$)$.

In the present study, three important pulmonary function indicators, namely FVC, FEV1, and MVV, were selected to comprehensively assess the effects of the two ventilation modes on postoperative pulmonary function. The results indicated that both groups of patients underwent a decline in pulmonary function postoperatively (preoperative $v s$. postoperative day 1 , day 3 , and day 5). However, the values of the pulmonary function indicators (FVC, MVV) of the patients in the SIMV group on postoperative days 1 and 3 were higher than those of the VCV group $(P<0.05)$, suggesting that the SIMV mode may have less pronounced effects on pulmonary function (Table 5).

Mechanical ventilation may cause different degrees of damage to the airway and lung tissues of the patients. The evaluation of the effects of the two ventilation modes on pulmonary infection and on the duration of hospitalization was achieved by measuring CPIS. The results indicated that the CPIS of the patients in the SIMV group was lower than that noted in the VCV group on postoperative days 1, 3, and $5(P<0.05)$, suggesting a lower risk of pulmonary infection and milder symptoms of the patients following SIMV (Figure 2). In addition, the duration of hospitalization and the extubation time were shorter in the SIMV group than in the VCV group $\triangle \mathrm{P}<0.05 \otimes$ (Table 2).

\section{Discussion}

Hip arthroplasty is currently the gold standard for the treatment of femoral neck fractures in elderly patients [2]. With the continuing development of surgical techniques and the improvement in artificial joint materials, the incidence of surgery-related complications in hip arthroplasty has gradually decreased [16]. However, elderly patients undergoing hip arthroplasty still tolerate surgery and anesthesia only poorly $[17,18]$. The risk of major organ and system complications is relatively high during the perioperative period in which respiratory, circulatory, and nervous system complications are common in this category of patients $[4,5]$.

Elderly patients undergoing hip arthroplasty are subject to several risk factors for PPCs. In addition to the patient's physiological changes and pre-existing respiratory diseases, mechanical ventilation during general anesthesia is also one of the important causes of PPCs $[13,19]$. Pressure generated by 
mechanical ventilation may have adverse effects on respiratory physiology and hemodynamics. Artificial airway ventilation causes a loss of the protective properties of the upper respiratory tract and destroys the defensive barrier between the patient's pharynx and trachea. In addition, inspiratory phase positive airway pressure pushes the secretions and bacteria from the upper respiratory tract backward to the bronchioles and alveoli, increasing the risk of pulmonary infection development in the patient [20]. Pulmonary injury caused by mechanical ventilation usually refers to barotrauma or volume injury [21]. Either an excessive increase in pressure or a volume increase can lead to an excessive increase in trans-pulmonary pressure and excessive stretching of the lung tissue, which, in essence, are caused by the expansion force.

Excessive expansion can also cause the release of inflammatory mediators and inflammatory cells in the lung tissue, resulting in pulmonary complications $[22,23]$. The patients that experience rapid development of high expansion force are prone to pneumothorax and mediastinal emphysema. High inspiratory flow rate, long mechanical ventilation and high oxygen concentration may also increase the incidence of pulmonary complications from different mechanisms.

Although VCV is one of the most commonly used modes of ventilation in anesthesia, its application has certain drawbacks [24]. It cannot achieve effective ventilation for small airways with low compliance, resulting in increased intrapulmonary shunt and imbalance of ventilation/blood flow. In addition, application of this ventilation mode is likely to cause high airway pressure in patients with relatively high requirements for general anesthesia and muscle relaxation. However, deep anesthesia and muscle relaxation increase the risk of delayed postoperative wake-up and delayed extubation in elderly patients. In the present study, SIMV was used, which is a mode commonly used in ICU for assisted ventilation and preparation for ventilator weaning for elderly patients undergoing hip arthroplasty.

Clinical trial showed that the airway peak pressure and platform pressure of SIMV ventilation mode were significantly lower than those of VCV mode at $0.5 \mathrm{~h}$ and $1 \mathrm{~h}$. The elderly patients in the SIMV group exhibited lower desynchronization between spontaneous breathing and ventilator airway pressure, and lower $\mathrm{AaDO}_{2}$ than those in the VCV group, indicating reduced impact on ventilation and respiratory function in the elderly patients during general anesthesia, which reduced the incidence of complications, such as hypoxemia and barotrauma to a certain extent. In addition, the SIMV mode prevented atrophy of respiratory muscles and movement disorders, thereby reducing the impact of mechanical ventilation on the cardiovascular system $[25,26]$.

Analysis of arterial blood gas is a reliable index that can be used to indicate the presence of acid-base imbalance, hypoxia, and the degree of hypoxia. Because the mechanisms underlying many types of physiological regulation are weaker in elderly patients, it is necessary to monitor blood gas dynamically to evaluate and maintain the stability of the internal environment in elderly patients undergoing general anesthesia mechanical ventilation or ventilator treatment. As shown from the data of the blood gas monitoring of the two groups of patients in the present investigation, patients in the VCV group showed higher partial pressure of carbon dioxide after operation than the patients in the SIMV group. First, VCV may lead to increased airway pressure and excessive expansion of lung tissues of the patients, which then caused further barotrauma or volume injury. Second, tension expansion damage may lead to the 
release of inflammatory transmitters in lung tissues. All these factors will lead to pulmonary ventilation and ventilation dysfunction, which causes accumulation of carbon dioxide to different degrees within the body.

Due to the long-term pre- and post-operative bedrest required for elderly patients undergoing hip arthroplasty, pulmonary function tests are often neglected. In the present study, we used a portable bedside spirometer to monitor the pulmonary function via three important pulmonary function indicators, namely FEV1, FVC, and MVV. The results indicated that compared with before operation, mechanical ventilation had different levels of effects on pulmonary function 1 day and 3 days after operation in patients in both groups, of which the forced vital capacity and the maximum spontaneous ventilation decreased more significantly in the VCV group, but the effect on the pulmonary function was less pronounced in the SIMV group and there was no significant difference between the two groups with respect to pulmonary function on the fifth day after operation. These results indicated that both ventilation modes can influence short-term postsurgical pulmonary function of elderly patients, but the influence of the SIMV mode was lower than that of the VCV mode.

CPIS is a scoring system with comprehensive clinical, imaging, and microbiological criteria to assess the severity of infection. This scoring system includes five indexes: body temperature, leucocyte count, airway secretions, oxygenation, and chest imaging. Evaluation of the postoperative pulmonary infection of patients in the two groups demonstrated that the CPIS of the patients in the SIMV group was lower than that in the VCV group, suggesting that SIMV provided lung-protective ventilation for the elderly patients undergoing hip arthroplasty, which may be related to the small effect of this ventilation mode on airway pressure, respiratory movement coordination, and respiratory system microenvironment in elderly patients.

However, application of SIMV ventilation mode in surgical anesthesia exhibits certain limitations. The SIMV mode that was used in the present study was mainly based on the selection of the anesthesia method. In the present study, the method of anesthesia used in the patients undergoing hip arthroplasty was mainly based on nerve blocks combined with deep sedation, and the operation time was not long. Therefore, application of SIMV mode may be debatable for cases with long operation time or endoscopy surgery.

\section{Conclusion}

In the present study we used SIMV to replace the traditional VCV mode in patients undergoing anesthesia of hip arthroplasty, and this mode improved postoperative pulmonary function and reduced PPCs, such as pulmonary infection, thereby achieving lung-protective ventilation. This mode should be used to optimize anesthesia-related strategies and consequently facilitate the rapid postoperative recovery of the patients.

\section{Declarations}




\section{Ethics approval and consent to participate}

The present study has been approved by the Medical Ethics Committee of the second hospital of Anhui Medical University, Hefei, China (Approval No: PJ2016-019-01). All patients signed written informed consent forms prior to their participation in the study protocol.

\section{Consent for publication}

Not applicable

\section{Availability of data and materials}

The datasets used and/or analysed during the current study are available from the corresponding author on reasonable request.

\section{Competing Interests}

The authors declare that they have no other competing interests.

\section{Financial Disclosures}

This study is supported by Priority Department of Second Affiliated Hospital of Anhui Medical University.

The funder's role is to provide financial support and verify the completion of the trial.

Funding: Science and Technology Project of Anhui Province (1704a0802165)

\section{Author Contributions}

YZ: This author helped conduct the study, analyze the data, write and revise the paper. (First author)

YL: This author helped design the study.

DF: This author helped analyze the data.

RL: This author helped conduct the study.

XWH: This author helped conduct the study.

YZ: This author helped design the study, write and revise the paper. (Corresponding author)

All authors read and approved the final manuscript

\section{Acknowledgements}

The authors are grateful to the participating patients. We also acknowledge the nursing team of our department for their excellent help with patient organization and nursing assistance. 


\section{Abbreviations}

VCV: volume-controlled ventilation

SIMV: synchronized intermittent mandatory ventilation

PPCs: postoperative pulmonary complications

CPIS: clinical pulmonary infection scores

ChicTR: Chinese Clinical Trial Registry

ASA: American Society of Anesthesiologists

BP: blood pressure

ECG: electrocardiogram

Sp02Пoxygen saturation

BIS: bispectral index

LMA: laryngeal mask airway

PETCO2: end-tidal $\mathrm{CO}_{2}$ pressure

PCIA: patient-controlled intravenous analgesia

VAS: visual analog scale

FVC: forced vital capacity

FEV: forced expiratory volume

MVV: maximal voluntary ventilation

AICU: Anesthesia Intensive Care Unit

Lac: lactic acid

PaC02: Partial pressure of carbon dioxide

\section{References}

1. Maradit Kremers H, Larson DR, Crowson CS, Kremers WK, Washington RE, Steiner CA, et al. Prevalence of Total Hip and Knee Replacement in the United States. J Bone Joint Surg Am 2015,97:1386-97. 
2. Chana R, Mansouri R, Jack C, Edwards MR, Singh R, Keller C, et al. The suitability of an uncemented hydroxyapatite coated (HAC) hip hemiarthroplasty stem for intra-capsular femoral neck fractures in osteoporotic elderly patients: the Metaphyseal-Diaphyseal Index, a solution to preventing intraoperative periprosthetic fracture. J Orthop Surg Res 2011,6:59.

3. Kim SM, Moon YW, Lim SJ, Yoon BK, Min YK, Lee DY, et al. Prediction of survival, second fracture, and functional recovery following the first hip fracture surgery in elderly patients. Bone 2012,50:1343-50.

4. Smith T, Pelpola K, Ball M, Ong A, Myint PK. Pre-operative indicators for mortality following hip fracture surgery: a systematic review and meta-analysis. Age Ageing 2014,43:464-71.

5. Frost SA, Nguyen ND, Black DA, Eisman JA, Nguyen TV. Risk factors for in-hospital post-hip fracture mortality. Bone 2011,49:553-58.

6. Qaseem A, Snow V, Fitterman N, Hornbake ER, Lawrence VA, Smetana GW, et al. Risk assessment for and strategies to reduce perioperative pulmonary complications for patients undergoing noncardiothoracic surgery: a guideline from the American College of Physicians. Ann Intern Med 2006,144:575-80.

7. Smetana GW. Postoperative pulmonary complications: an update on risk assessment and reduction. Cleve Clin J Med 2009,76 Suppl 4:S60-65.

8. Hamel MB, Henderson WG, Khuri SF, Daley J. Surgical outcomes for patients aged 80 and older: morbidity and mortality from major noncardiac surgery. J Am Geriatr Soc 2005,53:424-9.

9. Haines KL, Agarwal S. Postoperative Pulmonary Complications-A Multifactorial Outcome. JAMA Surg 2017,152:166-7.

10. Martin JB, Garbee D, Bonanno L. Effectiveness of positive end-expiratory pressure, decreased fraction of inspired oxygen and vital capacity recruitment maneuver in the prevention of pulmonary atelectasis in patients undergoing general anesthesia: a systematic review. JBI Database System Rev Implement Rep 2015,13:211-49.

11. Hartland BL, Newell TJ, Damico N. Alveolar recruitment maneuvers under general anesthesia: a systematic review of the literature. Respir Care 2015,60:609-20.

12. Neto AS, Hemmes SN, Barbas CS, Beiderlinden M, Fernandez-Bustamante A, Futier E, et al. Association between driving pressure and development of postoperative pulmonary complications in patients undergoing mechanical ventilation for general anaesthesia: a meta-analysis of individual patient data. Lancet Respir Med 2016,4:272-80.

13. Severgnini P, Selmo G, Lanza C, Chiesa A, Frigerio A, Bacuzzi A, et al. Protective mechanical ventilation during general anesthesia for open abdominal surgery improves postoperative pulmonary function. Anesthesiology 2013,118:1307-21.

14. Wallon G, Bonnet A, Guerin C. Delivery of tidal volume from four anaesthesia ventilators during volume-controlled ventilation: a bench study. Br J Anaesth 2013,110:1045-51.

15. Ghodrati M, Pournajafian A, Khatibi A, Niakan M, Hemadi MH, Zamani MM. Comparing the Effect of Adaptive Support Ventilation (ASV) and Synchronized Intermittent Mandatory Ventilation (SIMV) on 
Respiratory Parameters in Neurosurgical ICU Patients. Anesth Pain Med 2016,6:e40368.

16. Bilkhu A, Sisodia G, Chakrabarty G, Muralikuttan KP. Intramedullary fixation of a femoral shaft fracture with preservation of an existing hip resurfacing prosthesis. Injury 2015,46:763-6.

17. Zamora T, Klaber I, Bengoa F, Botello E, Schweitzer D, Amenabar P. [Management of hip fractures in the elderly. A national survey among Chilean orthopaedic surgeons]. Rev Med Chil 2019,147:199-205.

18. Gurger M. Factors impacting 1-year mortality after hip fractures in elderly patients: A retrospective clinical study. Niger J Clin Pract 2019,22:648-51.

19. Severgnini P, Bacuzzi A, Guzzetti L, Selmo G, Peluso L, Chiaranda M. Protective Ventilation in general anesthesia. Anything new? Rev Esp Anestesiol Reanim 2018,65:218-24.

20. Castro AA, Calil SR, Freitas SA, Oliveira AB, Porto EF. Chest physiotherapy effectiveness to reduce hospitalization and mechanical ventilation length of stay, pulmonary infection rate and mortality in ICU patients. Respir Med 2013,107:68-74.

21. Slutsky AS. History of Mechanical Ventilation. From Vesalius to Ventilator-induced Lung Injury. Am J Respir Crit Care Med 2015,191:1106-15.

22. Guldner A, Kiss T, Serpa Neto A, Hemmes SN, Canet J, Spieth PM, et al. Intraoperative protective mechanical ventilation for prevention of postoperative pulmonary complications: a comprehensive review of the role of tidal volume, positive end-expiratory pressure, and lung recruitment maneuvers. Anesthesiology 2015,123:692-713.

23. Fanelli V, Costamagna A, Carosso F, Rotondo G, Pivetta EE, Panio A, et al. Effects of liver ischemiareperfusion injury on respiratory mechanics and driving pressure during orthotopic liver transplantation. Minerva Anestesiol 2019,85:494-504.

24. Sen O, Bakan M, Umutoglu T, Aydin N, Toptas M, Akkoc I. Effects of pressure-controlled and volumecontrolled ventilation on respiratory mechanics and systemic stress response during prone position. Springerplus 2016,5:1761.

25. Ortiz G, Frutos-Vivar F, Ferguson ND, Esteban A, Raymondos K, Apezteguia C, et al. Outcomes of patients ventilated with synchronized intermittent mandatory ventilation with pressure support: a comparative propensity score study. Chest 2010,137:1265-77.

26. Tanaka R. [Strategy of mechanical ventilation for acute respiratory distress syndrome]. Masui 2013,62:532-40.

\section{Tables}

Table 1. Patient characteristics. The data represent the percentage of patients and mean (standard deviation). ASA=American Society of Anesthesiologists; BMI=Body Mass Index. VCV indicates Volume-controlled ventilation. SIMV indicates Synchronized intermittent mandatory ventilation. 


\begin{tabular}{lccc}
\hline & VCV $(n=31)$ & SIMV $(n=32)$ & $P$ value \\
\hline Gender $(n)$ & & & \\
Male & $18(58 \%)$ & $17(53 \%)$ & 0.6932 \\
\hline Female & $13(42 \%)$ & $15(47 \%)$ & 0.6932 \\
\hline Age (years) & $71.94 \pm 3.97$ & $72.22 \pm 3.47$ & 0.7637 \\
\hline BMI $\left(\mathrm{kg} \times \mathrm{m}^{-2}\right)$ & $23.06 \pm 2.03$ & $22.34 \pm 2.07$ & 0.1686 \\
\hline ASA score $(n)$ & & & \\
II & $25(81 \%)$ & $27(84 \%)$ & 0.6966 \\
\hline D & $6(19 \%)$ & $5(16 \%)$ & 0.6966 \\
\hline Nicotine dependence $(n)$ & $9(29 \%)$ & $11(34 \%)$ & 0.6488 \\
Alcohol abuse $(n)$ & $10(32 \%)$ & $11(34 \%)$ & 0.8586 \\
Comorbidity $(n)$ & & & \\
Hypertension $(n)$ & $12(39 \%)$ & $14(44 \%)$ & 0.6846 \\
\hline Diabetes mellitus $(n)$ & $5(16 \%)$ & $6(19 \%)$ & 0.7841 \\
\hline Others $(n)$ & $7(23 \%)$ & $8(25 \%)$ & 0.8217 \\
\hline \multicolumn{2}{c}{} \\
\hline
\end{tabular}

Table 2. Operative profiles. The data are presented as the mean (standard deviation)

VCV indicates Volume-controlled ventilation. SIMV indicates Synchronized intermittent mandatory ventilation.

\begin{tabular}{lccc}
\hline & $\operatorname{VCV}(n=31)$ & $\operatorname{SIMV}(n=32)$ & $P$ value \\
\hline Surgical profiles & & & \\
$\quad$ Surgery time $(\mathrm{min})$ & $106.39 \pm 10.53$ & $106.88 \pm 10.95$ & 0.8598 \\
\hline Anaesthesia time $(\mathrm{min})$ & $131.42 \pm 10.20$ & $131.75 \pm 10.79$ & 0.9026 \\
\hline Extubation time (min) & $9.68 \pm 4.67$ & $6.72 \pm 3.22$ & 0.0054 \\
\hline Fluid balance & & & \\
\hline Total amount (ml) & $700.00 \pm 161.64$ & $668.75 \pm 135.06$ & 0.4152 \\
\hline Length of hospital stay (days) & $8.71 \pm 1.59$ & $7.94 \pm 1.03$ & 0.0275 \\
\hline
\end{tabular}

Table 3. Intra-operative airway pressure. The data are presented as the mean and standard deviation; T0, T1 and T2 are representative of $5 \mathrm{~min}, 0.5 \mathrm{~h}$, and $1 \mathrm{~h}$, respectively, following the insertion of LMA

\begin{tabular}{lccc}
\hline & VCV $(n=31)$ & SIMV $(n=32)$ & $P$ value \\
\hline $\mathrm{T}_{0}$ & & & \\
P-peak $\left(\mathrm{cmH}_{2} \mathrm{O}\right)$ & $17.35 \pm 2.01$ & $17.25 \pm 1.80$ & 0.8307 \\
\hline P-plate $\left(\mathrm{cmH}_{2} \mathrm{O}\right)$ & $16.35 \pm 1.49$ & $15.66 \pm 1.27$ & 0.0529 \\
\hline $\mathrm{T}_{1}$ & & & \\
\hline P-peak $\left(\mathrm{cmH}_{2} \mathrm{O}\right)$ & $20.03 \pm 2.32$ & $17.94 \pm 2.03$ & 0.0004 \\
\hline P-plate $\left(\mathrm{cmH}_{2} \mathrm{O}\right)$ & $19.03 \pm 1.84$ & $17.09 \pm 1.88$ & 0.0001 \\
\hline $\mathrm{T}_{2}$ & & & \\
\hline P-peak $\left(\mathrm{cmH}_{2} \mathrm{O}\right)$ & $21.58 \pm 2.34$ & $19.09 \pm 2.05$ & $<0.0001$ \\
\hline P-plate $\left(\mathrm{cmH}_{2} \mathrm{O}\right)$ & $20.52 \pm 2.20$ & $18.47 \pm 1.75$ & 0.0002 \\
\hline
\end{tabular}


Table 4. Blood gas analysis. The data are presented as the mean and standard deviation. $\mathrm{PH}=$ pondus hydrogenii; $\mathrm{PaO}_{2}=$ partial pressure of oxygen in artery; $\mathrm{PaCO}_{2}=$ partial

pressure of carbon dioxide in artery; $\mathrm{HCO}^{-}=$hydrogen carbonate. $\mathrm{T} 0=$ prior to anesthesia induction, $\mathrm{T} 1=$ time period prior to extubation, $\mathrm{T} 2=$ Exit from the anesthesia intensive care unit (AICU), T3=postoperative day 1.

\begin{tabular}{|c|c|c|c|}
\hline & $\operatorname{VCV}(n=31)$ & $\operatorname{SIMV}(n=32)$ & $P$ value \\
\hline \multicolumn{4}{|l|}{$\mathrm{T}_{0}$} \\
\hline $\mathrm{PaO}_{2}(\mathrm{mmHg})$ & $71.71 \pm 4.90$ & $71.12 \pm 4.28$ & 0.6213 \\
\hline $\mathrm{PaCO}_{2}(\mathrm{mmHg})$ & $39.77 \pm 3.39$ & $38.94 \pm 2.87$ & 0.3023 \\
\hline $\mathrm{PH}$ & $7.39 \pm 0.03$ & $7.39 \pm 0.03$ & 0.9506 \\
\hline Lactic acid $\left(\mathrm{mmol} \mathrm{L}^{-1}\right)$ & $1.00 \pm 0.22$ & $0.98 \pm 0.22$ & 0.6135 \\
\hline $\mathrm{HCO3}^{-}\left(\mathrm{mmol} \mathrm{L}^{-1}\right)$ & $24.36 \pm 1.18$ & $24.34 \pm 1.21$ & 0.9628 \\
\hline \multicolumn{4}{|l|}{ 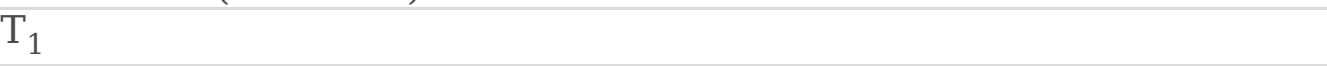 } \\
\hline $\mathrm{PaO}_{2}(\mathrm{mmHg})$ & $129.87 \pm 15.55$ & $133.19 \pm 13.53$ & 0.3773 \\
\hline $\mathrm{PaCO}_{2}(\mathrm{mmHg})$ & $38.10 \pm 3.12$ & $38.22 \pm 2.94$ & 0.8758 \\
\hline $\mathrm{PH}$ & $7.38 \pm 0.03$ & $7.40 \pm 0.02$ & 0.0019 \\
\hline Lactic acid $\left(\mathrm{mmol} \mathrm{L}^{-1}\right)$ & $1.14 \pm 0.26$ & $0.95 \pm 0.29$ & 0.0115 \\
\hline $\mathrm{HCO3}^{-}\left(\mathrm{mmol} \mathrm{L}{ }^{-1}\right)$ & $24.26 \pm 1.26$ & $24.30 \pm 0.98$ & 0.8854 \\
\hline \multicolumn{4}{|l|}{, } \\
\hline $\mathrm{PaO}_{2}(\mathrm{mmHg})$ & $84.00 \pm 12.19$ & $86.47 \pm 11.38$ & 0.4165 \\
\hline $\mathrm{PaCO}_{2}(\mathrm{mmHg})$ & $40.77 \pm 3.25$ & $38.97 \pm 2.84$ & 0.0242 \\
\hline $\mathrm{PH}$ & $7.41 \pm 0.03$ & $7.39 \pm 0.03$ & 0.0027 \\
\hline Lactic acid $\left(\mathrm{mmol} \mathrm{L}^{-1}\right)$ & $1.32 \pm 0.28$ & $1.15 \pm 0.23$ & 0.0116 \\
\hline $\mathrm{HCO3}^{-}\left(\mathrm{mmol} \mathrm{L}{ }^{-1}\right)$ & $24.71 \pm 1.08$ & $24.30 \pm 1.43$ & 0.2202 \\
\hline \multicolumn{4}{|l|}{ (1) } \\
\hline $\mathrm{PaO}_{2}(\mathrm{mmHg})$ & $71.00 \pm 5.32$ & $71.44 \pm 5.07$ & 0.7435 \\
\hline $\mathrm{PaCO}_{2}(\mathrm{mmHg})$ & $41.29 \pm 3.73$ & $39.16 \pm 2.68$ & 0.0126 \\
\hline $\mathrm{PH}$ & $7.41 \pm 0.03$ & $7.40 \pm 0.03$ & 0.0527 \\
\hline Lactic acid $\left(\mathrm{mmol} \mathrm{L}^{-1}\right)$ & $1.18 \pm 0.27$ & $1.05 \pm 0.26$ & 0.0605 \\
\hline $\mathrm{HCO3}^{-}\left(\mathrm{mmol} \mathrm{L}{ }^{-1}\right)$ & $24.14 \pm 1.21$ & $24.23 \pm 1.08$ & 0.7455 \\
\hline
\end{tabular}

Table 5. Perioperative pulmonary function. The data are presented as the mean and standard deviation. $\mathrm{FEV}_{1}=$ forced expiratory volume in 1 second; $\mathrm{FVC}=$ forced vital capacity; $\mathrm{MVV}=$ maximal voluntary ventilation. $\mathrm{T} 0=$ entering the operating room, $\mathrm{T} 1=$ postoperative day $1, \mathrm{~T} 2=$ postoperative day 3 , and $\mathrm{T} 3=$ postoperative day 5 . 


\begin{tabular}{|c|c|c|c|}
\hline & $\operatorname{VCV}(n=31)$ & $\overline{\operatorname{SIMV}}(n=32)$ & $P$ value \\
\hline \multicolumn{4}{|l|}{$\mathrm{T}_{0}$} \\
\hline $\mathrm{FEV}_{1}(\mathrm{~L})$ & $2.97 \pm 0.25$ & $2.93 \pm 0.23$ & 0.4873 \\
\hline FVC (L) & $3.35 \pm 0.26$ & $3.23 \pm 0.19$ & 0.0759 \\
\hline $\operatorname{MVV}(\%)$ & $53.46 \pm 5.11$ & $60.04 \pm 3.25$ & 0.0663 \\
\hline \multicolumn{4}{|l|}{$\mathrm{T}_{1}$} \\
\hline $\mathrm{FEV}_{1}(\mathrm{~L})$ & $2.80 \pm 0.22$ & $2.74 \pm 0.23$ & 0.3546 \\
\hline FVC (L) & $2.97 \pm 0.24$ & $3.12 \pm 0.20$ & 0.0100 \\
\hline $\operatorname{MVV}(\%)$ & $46.40 \pm 4.58$ & $52.75 \pm 3.62$ & 0.0373 \\
\hline \multicolumn{4}{|l|}{$\mathrm{T}_{2}$} \\
\hline $\mathrm{FEV}_{1}(\mathrm{~L})$ & $2.94 \pm 0.18$ & $2.90 \pm 0.26$ & 0.5259 \\
\hline FVC (L) & $3.07 \pm 0.23$ & $3.18 \pm 0.16$ & 0.0211 \\
\hline $\operatorname{MVV(\% )}$ & $48.97 \pm 3.26$ & $53.20 \pm 3.16$ & 0.1534 \\
\hline \multicolumn{4}{|l|}{$\mathrm{T}_{3}$} \\
\hline $\mathrm{FEV}_{1}(\mathrm{~L})$ & $2.93 \pm 0.16$ & $2.98 \pm 0.12$ & 0.1973 \\
\hline FVC (L) & $3.09 \pm 0.23$ & $3.19 \pm 0.21$ & 0.0887 \\
\hline MVV(\%) & $54.19 \pm 4.27$ & $56.61 \pm 5.15$ & 0.0508 \\
\hline
\end{tabular}

\section{Figures}

\section{Figure 1}

Flow diagram of the experimental scheme. VCV stands for volume-controlled ventilation. SIMV stands for synchronized intermittent mandatory ventilation.

\section{Figure 2}

Patient clinical pulmonary infection scores (CPIS). CPIS were reviewed on postoperative day 1 (T1), postoperative day 3 (T2), and postoperative day 5 (T3) in order to evaluate the number of pulmonary infections. CPIS included five indices as follows: temperature, white blood cell count, excretion, oxygenation index, and chest X-ray. Higher scores indicate more severe pulmonary infection.

\section{Supplementary Files}

This is a list of supplementary files associated with this preprint. Click to download.

- CONSORT2010Checklist.doc 